\title{
Type in motion: The representation of the illocutionary force through the expression of the kinetic typographic form
}

\section{SIGRADI2018 TECHNOPOLITICAS \\ xxii congresso da sociedade iberoamericana de gráfica digital 22th conference of the iberoamerican society of digital graphics $07|08| 09 \mid$ novembro|2018 iau usp | são carlos | sp br}

\author{
María Cecilia Brarda \\ Facultad de Arquitectura, Diseño y Urbanismo - Universidad Nacional del Litoral | Argentina | \\ mcbrarda@gmail.com
}

\begin{abstract}
The objective is to analyze how type in motion contributes to the representation and transmission of the illocutionary force of a statement in the field of communication and digital animation. This is a context characterized by being a hybrid of image and sound, of a esthetic and technological diversity and mixtures of representation techniques and animation of different types of motion graphics. The expressive form of the signs of writing is crossed by the variables time, movement and sound and from here their ability to transmit the illocutionary force is enhanced.
\end{abstract}

Keywords: Typography in movement; Illocutionary force; Kinetic writing; Digital animation; Typographic form.

\section{INTRODUCCIÓN}

El objetivo de este artículo es analizar de qué manera la tipografía en movimiento contribuye a la representación y trasmisión de la fuerza ilocucionaria de un enunciado en el campo de la comunicación y animación digital.

Se parte del concepto de fuerza ilocucionaria (Austin, 2003) que, siendo propio de la oralidad, ha de perderse en parte en el texto escrito porque la escritura no representa bien cómo deben interpretarse los textos (Olson, 1998). Sin embargo, recuperar la fuerza ilocucionaria es una de las condiciones de la tipografía y del diseño gráfico (Gorodischer, 2010). A partir de aquí se conjetura que la tipografía en movimiento dispone de otros recursos y dimensiones para representar, con mayor profundidad que la estática, dicha fuerza.

El área donde opera la tipografía en movimiento se caracteriza por ser un híbrido de imagen y sonido, de diversidad estética y tecnológica, y de mixturas de técnicas de representación y modos animación de la imagen en movimiento. Es así que, para este tipo de escritura cinética, la sustancia de producción de sentido es el tiempo: hay un tiempo en el que transcurre, otro en el que permanece, luego desaparece o se transforma; consiguiendo así un carácter efímero como el habla. A partir de aquí, la valoración de la cualidad significante del signo escrito implica pensar que la expresión de la forma sea en torno a la problemática del movimiento y la transformación de los signos lingüísticos a lo largo del tiempo con una duración para ser leídos. La figuración y significación de la letra (Barthes, 1986) —que habían estado más ligadas al carácter espacial y a las posibilidades de representación como signo tipográfico (estático) y en su función en relación al espacio de una composición (bidimensional, estática) - son atravesadas por las variables tiempo, movimiento y sonido, y la tipografía, en tanto imagen, se vuelve protagonista de las piezas de comunicación y animación digital.

\section{LA FORMA TIPOGRÁFICA COMO EXPRESIÓN DE LA FUERZA ILOCUCIONARIA}

David Olson dice que mientras que los enunciados orales tienden a indicar lo que se dice y, al mismo tiempo, cómo deben ser interpretados, los enunciados escritos tienden a especificar sólo lo primero porque no representan cómo deben interpretarse. Es difícil representar el énfasis y la entonación en una escritura porque esos rasgos están distribuidos a lo largo de todo el enunciado y entretejidos con él en el caso de los enunciados orales. Si bien la escritura proporciona un modelo razonable de lo que el hablante dice, no provee un modelo razonable de lo que el hablante quiere decir, o más precisamente cómo el hablante o el autor pretenden que sea interpretado su enunciado. Esto es así porque la escritura no representa bien lo que se conoce técnicamente como fuerza ilocucionaria; que constituye uno de los aspectos de un enunciado que un oyente puede detectar, por lo general, en el discurso oral. (Olson,1998, p. 115-116)

Las pistas - prosódicas y paralinguísticas - incluyen la entonación, el acento y calidad de voz, el estado de ánimo del hablante, sus dudas y reservas o el peso acordado para cada parte de su argumento. (Olson, 1998, p. 119). Entonces, para que esta información se devele, el texto debe ser editado por un comentario descriptivo o un metalenguaje que indique cómo debe interpretarse ese texto. Por ejemplo, si en una conversación oral un hablante le dice a otro: "llegas tarde" seguramente lo hace con un tono de voz particular, gesticulando de 
alguna manera o teniendo alguna mirada en particular, es decir incorporando una fuerza ilocucionaria que expresa la intención y estado de ánimo de ese enunciado. Para que esto último ocurra, si la frase "llegas tarde" está escrita, (además de los correctos usos de signos de puntuación, exclamación o interrogación), deberían agregarse otros enunciados tales como "lo dijo seriamente", o "lo decía preocupado", o "le reclamó enojado" así, mediante estas explicaciones, puede interpretarse mejor ese acto de habla.

Continuando con los planteos de Olson, Gorodischer (2010) explica que la tipografía y el diseño gráfico recuperan la fuerza ilocucionaria en sus funciones comunicativas. Retoma también, la idea de edición y metalenguaje que, según Olson, un texto necesita para ser entendido y conjetura que el diseño gráfico puede considerarse como un conjunto de instrumentos, métodos y formalizaciones que hace posible explicitar dicha fuerza, que en principio, no está presente en la escritura.

Ahora bien, focalizando en uno de los aspectos de la tipografía se puede decir que, desde su forma expresiva, ha contribuido a dar respuesta a este problema ya que, como dice Andreu Balius (2010), "la tipografía es la voz del texto y le aporta contenido más allá de lo que el propio texto trasmite". Se parte de la definición de Calles (2005) que dice que la tipografía posee dos funciones, una lingüística y una simbólica. La primera se ocupa de la consignación de la palabra en un hecho gráfico, estrictamente en una permutación visual del lenguaje; al mismo tiempo, la función simbólica opera sobre la imagen y expresión plástica de la palabra. A partir de la interacción de ambas funciones y de la combinación de las propiedades semánticas del contenido verbal y la expresión formal se genera la producción e interpretación de los signos tipográficos.

A partir de estas definiciones y continuando con el planteo de Gorodischer, se puede afirmar que la función simbólica de la tipografía — revelada a partir de la forma externa del signo escrito- también constituye una pista prosódica que sustituye la opción de agregar un metalenguaje para la interpretación del texto. Siguiendo a Olson, que dice que los textos requieren de alguna determinación explícita de la fuerza ilocucionaria para que puedan explicarse como literales o metafóricos (Olson, 1998, p. 213), se puede añadir que esa función simbólica constituye esa determinación explícita orientada a intentar representar la acentuación, entonación y pronunciación del texto, aportando así a trasmitir la fuerza ilocucionaria.

\section{¿CÓMO ES LA FORMA DE LA LETRA?}

Para hacer referencia a la forma de la expresión de la letra, en principio, en el plano de la espacialidad y la bidimensión, en este análisis se hablará en términos de sustancia. Esto se explica, a grandes rasgos, caracterizando nuevamente la función de la letra en dos grandes grupos. Por un lado, la letra en su puridad como imagen de sí misma, ya sea en su forma caligráfica o tipográfica, analógica o digital, tal como fue diseñada por el tipógrafo o escrita por el calígrafo. Por otro lado, la letra como imagen intervenida con otra sustancia, es decir, la forma pura es interpelada por sustancias externas a su propia imagen como texturas, colores, objetos, acciones (deformada, estirada, etc.). Estas expresiones formales de las letras son apropiadas en la medida en que siempre se sigan reconociendo como letras.

Montesinos y Mas Hurtuna en Manual de Tipografía, del plomo a la era digital, refieren a tipografía de edición para la primera y tipografía creativa para la segunda. Sostienen que la primera reúne cuestiones tipográficas relacionadas con las familias, tamaños, espaciados entre letras y palabras, interlineados, entre otras cosas que hacen a que su primer objetivo sea la legibilidad. Mientras que la tipografía creativa ya que dispone de otros recursos: "contempla la comunicación como si se tratara de una metáfora visual, donde el texto no sólo tiene una funcionalidad lingüística, y donde, a veces se representa de forma gráfica, como si se tratara de una imagen" (Montesinos \& Mas Hurtuna, 2005, p. 18).

En ambos casos las letras como signos de escritura son portadoras de mensajes lingüísticos, pero en el primero la lectura del contenido del texto y su legibilidad es la principal función mientras que, en el segundo, "el significante se impone por medio de la expresión" (Sesma, 2004, p. 39) y la letra adquiere esa función simbólica o metafórica que mencionaba Calles, es decir, deja de ser imagen de sí misma para ser imagen de otra cosa y significar algo más. Dicho en otras palabras, a través de una expresión metafórica de la forma de su sustancia la letra adquiere un sentido que va más allá del propio texto o, como explica Sesma, "la letra - en su verbalidad- hace uso del grafismo para representar características metalingüísticas" (Sesma, 2004, p. 38). Esta sería otra manera de caracterizar a la ya mencionada función simbólica.

\section{LA LETRA COMO EL ESPACIO DE LA FIGURACIÓN}

Barthes toma a la letra en su vocación de metamorfosis figurativa y se pregunta: ¿Duplica acaso la imagen ciertas informaciones del texto por un fenómeno de redundancia o bien es el texto el que añade información inédita a la imagen? Las letras del alfabeto han adquirido relaciones metafóricas con otras cosas que ya no son letras. $Y$ afirma que existe un espíritu de la letra, que vivifica a la propia letra. También dice que el espíritu es el espacio del sentido ${ }^{1}$ : el espíritu de un fenómeno, de una palabra, no es más que su derecho a empezar a significar. En la relación entre letra y figura: en ella se agota toda lógica 0 la letra es la figura, por ejemplo la B es una mujer que abraza una serpiente; o la figura está dentro de la letra, envainada en ella por completo; o la letra está adentro de la figura. (Ver Figura 1).

Barthes se pregunta: la escritura está hecha de letras, de acuerdo, pero la letra ¿de qué está hecha? Afirma, entonces, que la letra es un híbrido. Tiene un carácter poético, que es la capacidad simbólica de una forma. Esta capacidad no tiene valor más que en la medida en que permite a la forma partir en un gran número de direcciones y manifestar así, en potencia, un avance infinito del símbolo, que jamás puede constituir un significado último y que es siempre, en suma, el significante de otro significante.

\footnotetext{
${ }^{1}$ Barthes habla del espacio del sentido, de lo poético y lo simbólico en relación al análisis que viene haciendo sobre la figuración de la letra en el alfabeto de Erté en el capítulo "El espíritu de la letra" de su libro Lo obvio y lo obstuso, 1992.
} 


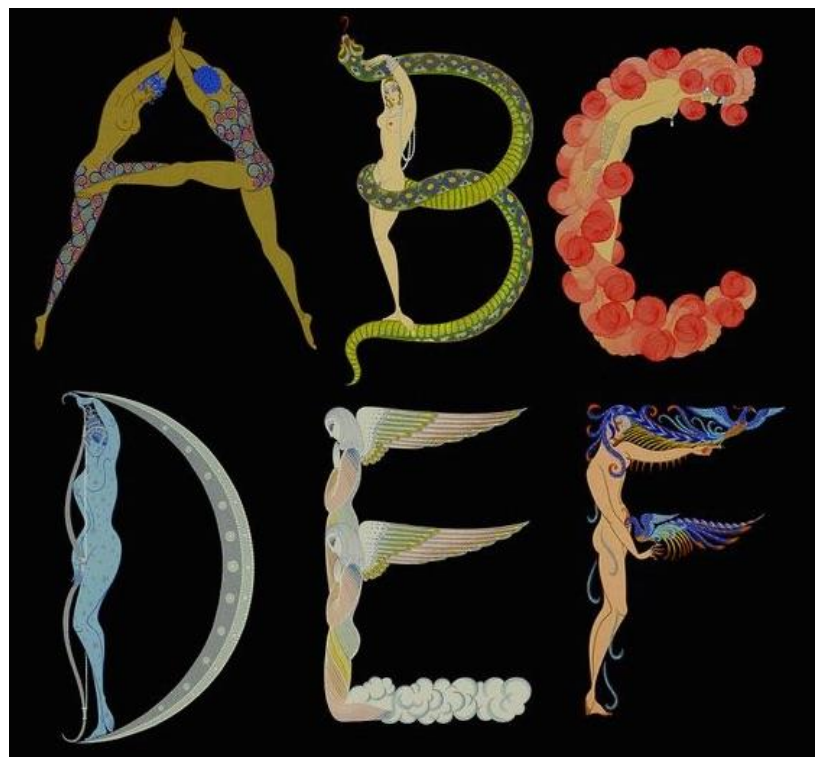

Figura 1: Fragmento de "The alphabet", Erté 1976

La figuración de la letra en tanto estática y bidimensional se refiere a que la imagen (que no es signo verbal) se supedita al espacio que otorga la estructura formal de la letra y cuando se incorpora allí queda, a veces inmóvil, a veces eterna. Como una escultura, la figura adaptada a las astas, a los remates, a los ángulos, su forma expresiva es en razón de esa estructura, anatomía interna, que la letra impone. Por esto, en el alfabeto que Barthes analiza de Erté dice ¿no se disponen los dos cuerpos como dos iniciales entrelazadas en el mismo espacio?

Sin embargo, cuando se trata de la dimensión temporal, esto puede pasar o no, porque el espacio ya no es el mismo que el de la imagen fija. Aquí hay un espacio narrativo, que se adapta al tiempo de la imagen. Un espacio cambiante e infinito. En un momento es el espacio de la imagen y al instante es el espacio del texto. Aunque a veces coinciden y otras veces no. En la imagen estática, siempre coinciden.

\section{VANGUARDIAS}

La experimentación tipográfica trasgrede el sistema lingüístico y romper con el orden y la sintaxis en el diseño de la página fue tarea de algunas vanguardias del siglo $X X$ que concibieron a la letra como imagen polisémica y cuyos valores estéticos prevalecían sobre los de uso del texto. Las obras tipográficas de las vanguardias artísticas -Futurismo, Dadaísmo, Constructivismo- ilustran esta cuestión y lo expresan desde sus manifiestos hasta en sus obras de diseño gráfico y tipográfico donde el principal objetivo es romper las estructuras de la página y formas tradicionales de escritura y lectura.

Vale destacar que, como antecedente en Latinoamérica, en los años 50' se destaca en Brasil la Poesía Concreta de la mano del Grupo Noigrandes, encabezado por el poeta Agusto de Campos. Sus obras generaron un quiebre en los modos formales de escribir los versos. Esto lo conseguía a través del uso de distintos recursos gráficos, colores, tipos de letras y modos de componer con palabras en la página. (Ver Figura 2).

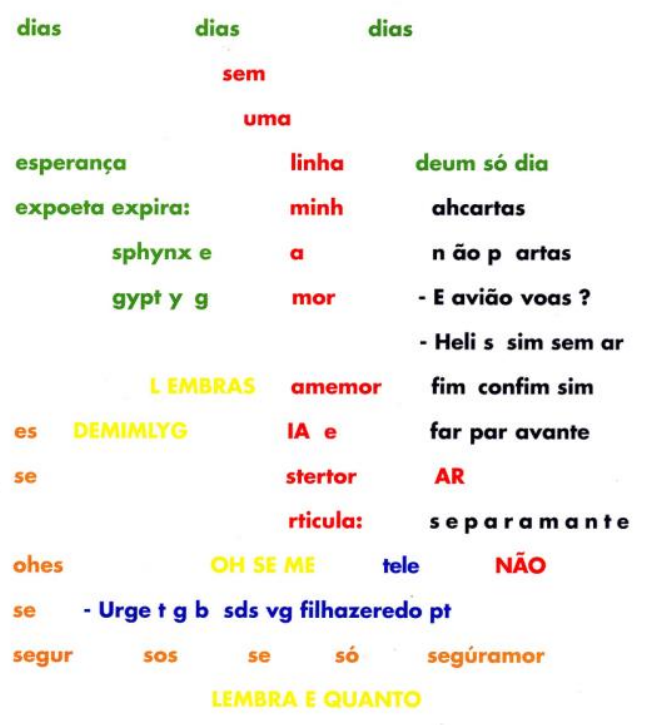

Figura 2: "Poetamenos", Agusto de Campos 1953

\section{TYPE IN MOTION. LA REPRESENTACIÓN DE LA FUERZA ILOCUCIONARIA A TRAVÉS DE LA EXPRESIÓN DE LA FORMA TIPOGRÁFICA CINÉTICA}

A partir del avance de la era digital y de los nuevos medios de comunicación la tipografía pasó a ser un componente elemental del diseño de comunicación en pantalla (Hillner, 2010) y por eso ha ido adoptando otras formas de expresión de la escritura, entre ellas la tipografía cinética o tipografía en movimiento. La que, habiendo tenido sus primeras apariciones en las secuencias de créditos cinematográficos en los años 50', adquiere un potencial expresivo inusitado como objeto principal de expresión formal y semántica en piezas digitales.

Matthias Hillner (2010), en su libro Tipografía Virtual, dice que la tipografía en movimiento es el término que se le asigna principalmente a la tipografía que se usa para la comunicación en pantalla, que se trata de una "tipografía dinámica en sí misma" y la señala como "letras que se mueven". Mientras que Matt Woolman $(2000,2005)$ en sus dos libros sobre Type in motion, habla de "tipografía animada" y afirma que es "la aparición secuencial en pantalla de las unidades de un texto de tal forma que sea coherente su lectura". Por lo que cabe preguntarse si es una condición que todos los textos cinéticos sean legibles, es decir, que se puedan leer.

El espacio de la escritura cinética es un espacio híbrido que, por un lado, repercute en la expresión de la forma de la tipografía que cambia a partir de las variables tiempo, movimiento y sonido; y, por otro lado, puede provocar cambios en los modos de lectura. En esta hibridación del lenguaje tipográfico cinético, la forma de las letras deben pensarse en torno a la problemática del movimiento y la transformación, mientras se desarrollan de un modo coherente y legible a lo largo del tiempo.

A través de la dimensión cinética de la escritura se puede representar el énfasis y la entonación del enunciado debido a la forma de expresión metafórica de la tipografía en movimiento y a su función intentar trasmitir una idea más allá del texto. La tipografía cinética no necesita 


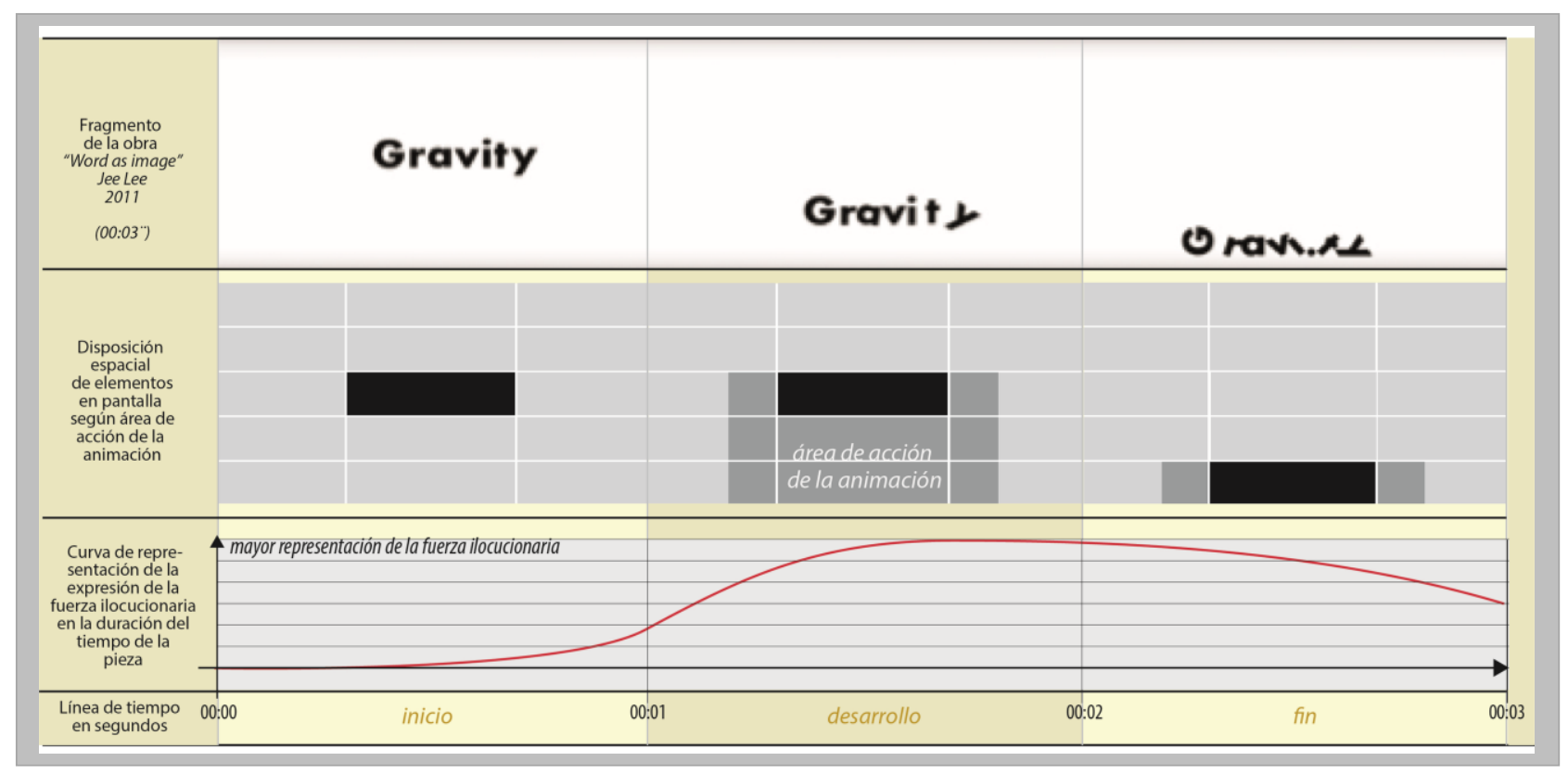

Figura 3: Fragmento de la pieza "Word as image" de Jee Lee (2011). Curva expressiva que representa la fuerza ilocucionaria.

recurrir a otro texto explicativo para mostrar cómo es la intensión del hablante, porque en su modo de expresarse, por su qualia (Oliveras, 2010) que le es propia, la revela. Entonces, ¿cómo es la expresión de la forma de los signos de escritura en la tipografía cinética? $\mathrm{Y}$, cuando dicha forma de la expresión es atravesada por las variables tiempo, movimiento y sonido ¿fortalece a la trasmisión de la fuerza ilocucionaria?

En la escritura cinética, ¿Qué es lo que se mueve? ¿La letra, la palabra, el texto o todo junto? ¿Qué cambios genera el movimiento en esos signos de escritura y cómo es ese movimiento? ¿Permite otros modos de lectura?

\section{METODOLOGÍA}

Se seleccionaron tres piezas audiovisuales de tipografía en movimiento para analizar cómo la expresión de la forma temporal de los signos de escritura sincronizada con música o efectos sonoros potencia la trasmisión de la fuerza ilocucionaria en las palabras o textos de dichas piezas. Para ello se construyó una herramienta de análisis exhaustiva que integra la teoría de escritura de Harris (1999) -formación, procesamiento, interpretación- con aspectos sintácticos, morfológicos y semánticos provenientes del diseño y comunicación visual, de la tipografía y del cine de animación. Se profundizó en las instancias narrativas y expresivas de la forma tipográfica en movimiento, en los modos de representación del texto como imagen y de la imagen como texto y en aquellos atributos interdisciplinarios que entran en juego en el proceso de significación aportan especial expresión para trasmitir la fuerza ilocucionaria.

La herramienta de análisis es un cuadro que entrecruza las instancias de formación, procesamiento e interpretación (Harris 1999) con las etapas del relato clásico cuya narración lineal se estructura en inicio, desarrollo y fin. Las piezas audiovisuales elegidas tienen este tipo de estructura narrativa que es también la que adquiere el signo escrito al desarrollarse temporalmente por medio de la animación, y lo hace tanto en la unidad de la letra como en la totalidad de la palabra y los textos.

Según la teoría de Harris en la primera instancia, la de formación, se reconocerá aquella actividad a partir de la cual se produce el signo escrito teniendo en cuenta las características propias del medio donde se expresa, en este caso sería la pieza audiovisual. Por esto, se presta atención a cómo se representa, con qué familia tipográfica, si hay ilustración, cómo es la animación, qué técnica, tecnología o material se utiliza. En la segunda instancia, que es la de procesamiento, se reconoce lo que hace posible la lectura de esa forma escrita, es decir, cómo se lee la palabra en relación a la animación y al tiempo en que permanece estática para su lectura. La tercera es la de interpretación, engloba lo anterior y además indica qué atributos formales ayudan a la misma. Para analizar esta instancia se crea la curva de expresión de la fuerza ilocucionaria cuya extensión abarca toda la duración del relato. De esta manera, se puede vislumbrar con qué potencia y en qué momentos se trasmite dicha fuerza a través de la forma tipográfica cinética. Para esto, se hace foco en el momento de mayor énfasis de la curva dramática del relato animado, que sería momento de la acción representada que, en algunos casos, es enfatizada con música y efectos sonoros.

\section{ANÁLISIS DE OBRAS}

Las piezas audiovisuales de tipografía cinética seleccionadas para este análisis se clasifican por la función en ellas de la letra, la palabra y del texto.

\section{PALABRA CINÉTICA, "GRAVITY"}

Se ha seleccionado la animación de la palabra "Gravity" (ver Figura 3), fragmento que corresponde a la obra "Word as Image" de Jee Lee (2011). En esta pieza, la palabra Gravity (gravedad) se trasmite la fuerza ilocucionaria de manera visible a través de la animación tipográfica y el sonido. La pieza tiene una duración de tres a cuatro segundos. En todo momento se reconoce el signo tipográfico. La alteración o intervención en la 


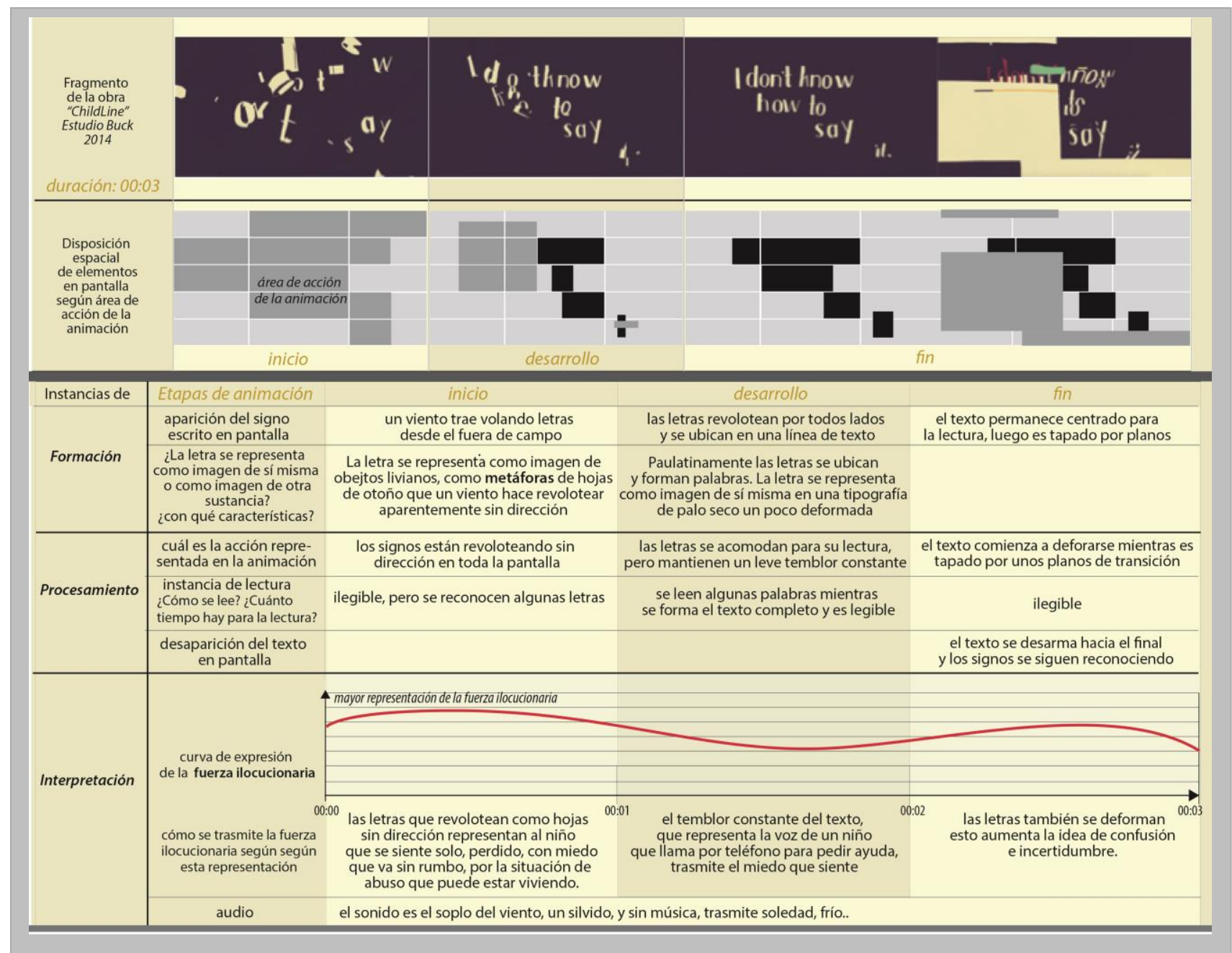

Figura 4: Cuadro de análisis de un fragmento de ChildLine, (Estudio Buck, 2015).

Este cuadro es la herramienta metodológica utilizada también en los otros dos ejemplos (Fig. 3 y fig.5).

forma de la tipografía es mínima. El valor semántico se atribuye en mayor medida a la animación, al ritmo y, en especial, al sonido. El sonido en varias ocasiones porta información que revela con mayor claridad que la animación el significado de dicha palabra, expresando así la fuerza ilocucionaria de manera más directa que la imagen

En la instancia de formación del signo escrito se analiza que la letra se representa como imagen de si misma en una tipografía Futura. Los signos son en negro sobre fondo blanco. En el inicio, la palabra está estática en el centro de la pantalla y de repente, por la fuerza de gravedad, los caracteres se caen y hacen ruido, tenían un peso. Así es el cuadro del final: las letras caídas, tiradas al borde inferior de la pantalla. En este último segundo, en la composición final, la palabra "gravity" se sigue reconociendo, es una imagen estática y en esta composición tipográfica final también trasmite la fuerza ilocucionaria de la caída. Sin embargo, el momento de mayor representación de dicha fuerza (instancia de desarrollo) es con la animación y el sonido del golpe de las letras al caer, que además las muestra como pesadas.

\section{TEXTO CINÉTICO, “CHILDLINE”}

Para analizar una línea de texto representada en tipografía en movimiento se tomó un fragmento de la pieza ChildLine —creada por el Estudio Buck en 2015(ver Figura 4), que es una animación promocional de una empresa de asesoramiento para menores víctimas de abuso sexual. Este tema se representa a través de un diálogo entre un menor y un adulto de dicha empresa. El diálogo está representado a través de una tipografía creativa animada con cortas escenas y una limitada paleta de colores. Cuando se representa la voz del menor las palabras se representan con diferentes animaciones tipográficas y las letras se convierten en metáforas de otras imágenes que expresan distintas sensaciones y estados de ánimo que, sincronizadas con la música y los efectos sonoros, consiguen cautivantes escenas; mientras que, cuando habla el adulto, la tipografía de tipo trazo manual es siempre la misma, sin animar, es legible y homogénea. El color también juega un papel importante para distinguir a los interlocutores. Por ejemplo: en las escenas cuando habla el niño, el color de fondo que prevalece es un violeta oscuro, mientras que, cuando habla el adulto, resalta un color marfil claro, marcando siempre un alto contraste entre escena y escena.

En este relato se destaca la sincronización del sonido con la tipografía en movimiento ya que juegan un importante 


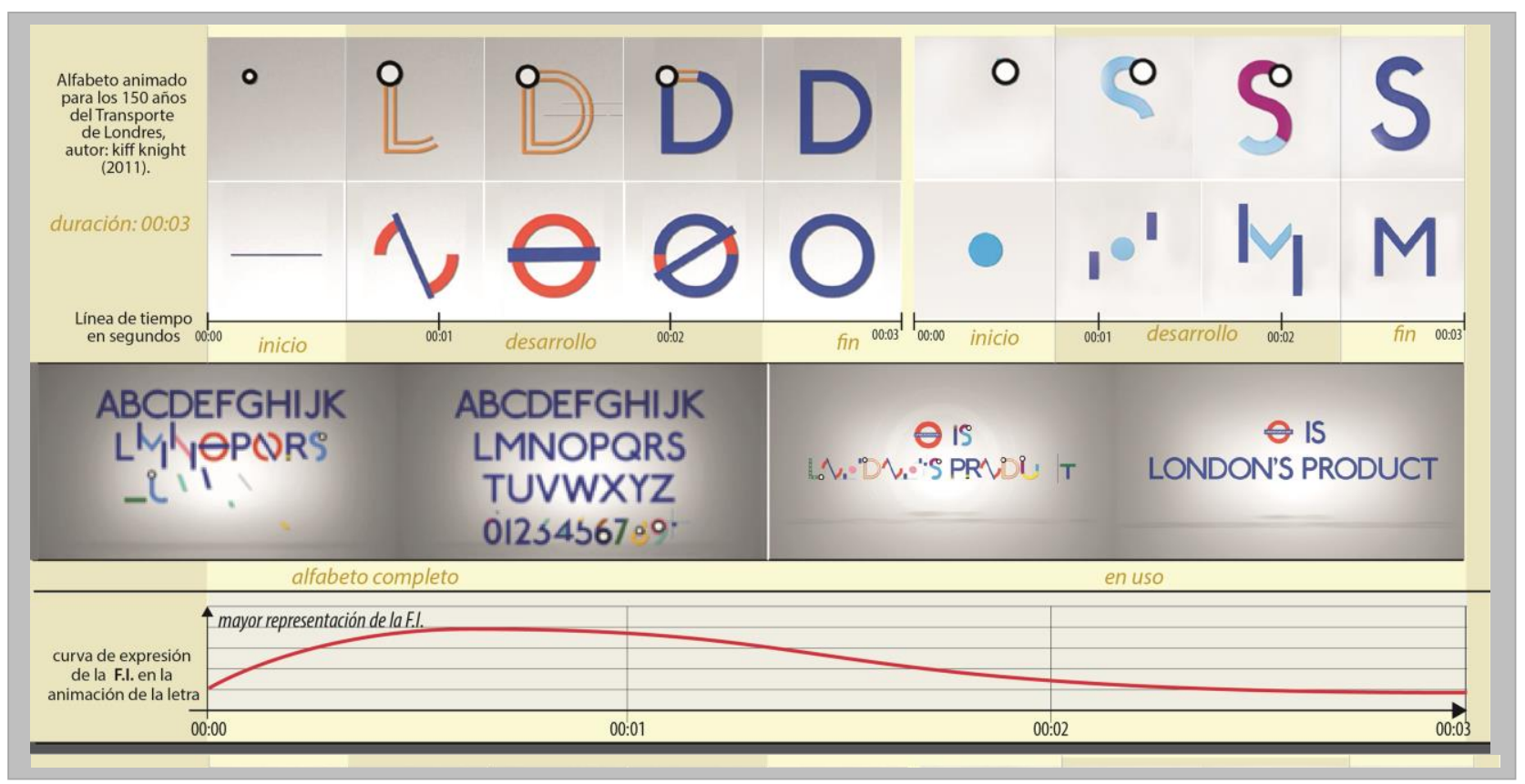

Figura 5: Alfabeto cinético. Curva de expresión de la fuerza ilocucionaria representada en la animación de las letras del alfabeto. Autor: Kiff knight (2011)

papel como componentes expresivos para potenciar la trasmisión de la fuerza ilocucionaria. La música, carga de significado a la representación de cada palabra animada, reforzando enérgicamente las sensaciones que la pieza busca causar en el espectador. Así mismo, es un separador entre escenas: cuando habla el niño hay una música acompañada de efectos sonoros que representan su estado de ánimo: el de un niño que sufre en su casa porque es abusado sexualmente. Se trata de una composición musical que genera una idea de misterio, incertidumbre, vértigo, desconsuelo, peligro. También hay espacios de silencio que cargan la pieza de momentos dramáticos expresando soledad y miedo. Cuando el adulto responde, la música toma un tono armonioso, sereno, relajante, consolador, procurando trasmitir seguridad a ese niño que no la tiene.

A los fines de este enfoque se hizo un recorte de cuatro segundos donde se visualiza una línea de texto correspondiente a la voz del niño. La frase dice "Yo no sé como decirlo" y hace referencia a la dificultad del niño para contar su problema. Desde la instancia de formación, se analiza cómo entra la escritura en pantalla. Las letras entran en pantalla revoloteando como hojas que el viento hace volar sin rumbo ni dirección. Se ubican formando las palabras. De esta manera, el texto con un temblor constante representa la voz del sujeto que está sufriendo. La escritura cinética consigue trasmitir un tono de incertidumbre. Aquí la curva de la fuerza ilocucionaria alcanza su punto más alto de expresión respecto a esta escena, ya que demuestra claramente ese estado de ánimo que la tipografía está buscando representar. El texto permanece unos segundos para su lectura y luego las letras se deforman al mismo tiempo que son tapadas por unos planos que son la transición a la siguiente escena.

\section{ALFABETO CINÉTICO}

Para analizar la expresión de la forma del signo de escritura en la unidad de la letra se eligió este alfabeto cinético diseñado por los 150 años del subterráneo de
Londres por Kiff knight (2011), (ver Figura 5). Aquí la forma de la tipografía cinética es una metáfora de la representación de los mapas de subtes. En la instancia de formación del signo alfabético, en el inicio de la animación, este aún no se reconoce como tal puesto que está siendo significante de otro significante (Barthes, 1986). Es decir que, como imagen de otra cosa, la letra aún no es letra, por ejemplo, la letra "o" en la mitad de la animación reconstruye la forma del reconocido logo del "Underground" de Londres. Durante el desarrollo, los trazos que dibujarían a las astas y demás partes de la tipografía están representando a las líneas del subterráneo que aparecen en el mapa en sus diferentes colores y texturas. Además el sonido de fondo de trenes refuerza esta idea. Desde el inicio cada signo tiene una animación diferente que recorre el ductus propio de la forma de cada letra que está construyendo. Sin embargo, hacia el final de la animación, los signos quedan fijos y se entiende que todos pertenecen a una misma familia tipográfica del tipo Futura en mayúsculas y en color azul. De esta manera, cuando este alfabeto se utiliza para textos, los mismos comienzan con una animación por cada carácter pero hacia el final la lectura es clara y legible. Por esta razón, la tipografía cinética en este alfabeto, alcanza la cima de la curva de expresión de la fuerza ilocucionaria en la instancia de formación inicial y desarrollo. (Ver Fig. 5)

\section{RESULTADOS}

La recuperación de la fuerza ilocucionaria de un texto se puede conseguir a través de la forma de la expresión de la letra y esto puede generarse tanto en el plano de la espacialidad como en el de la temporalidad. Respecto al primero, quedó claro que se demuestra con la función simbólica de la letra. En el segundo, además de dicha función, la forma de la expresión de la letra es atravesada por las variables propias del medio digital y desde ahí la recuperación de la fuerza ilocucionaria se gesta de otra manera. Así ocurre con la tipografía cinética. 


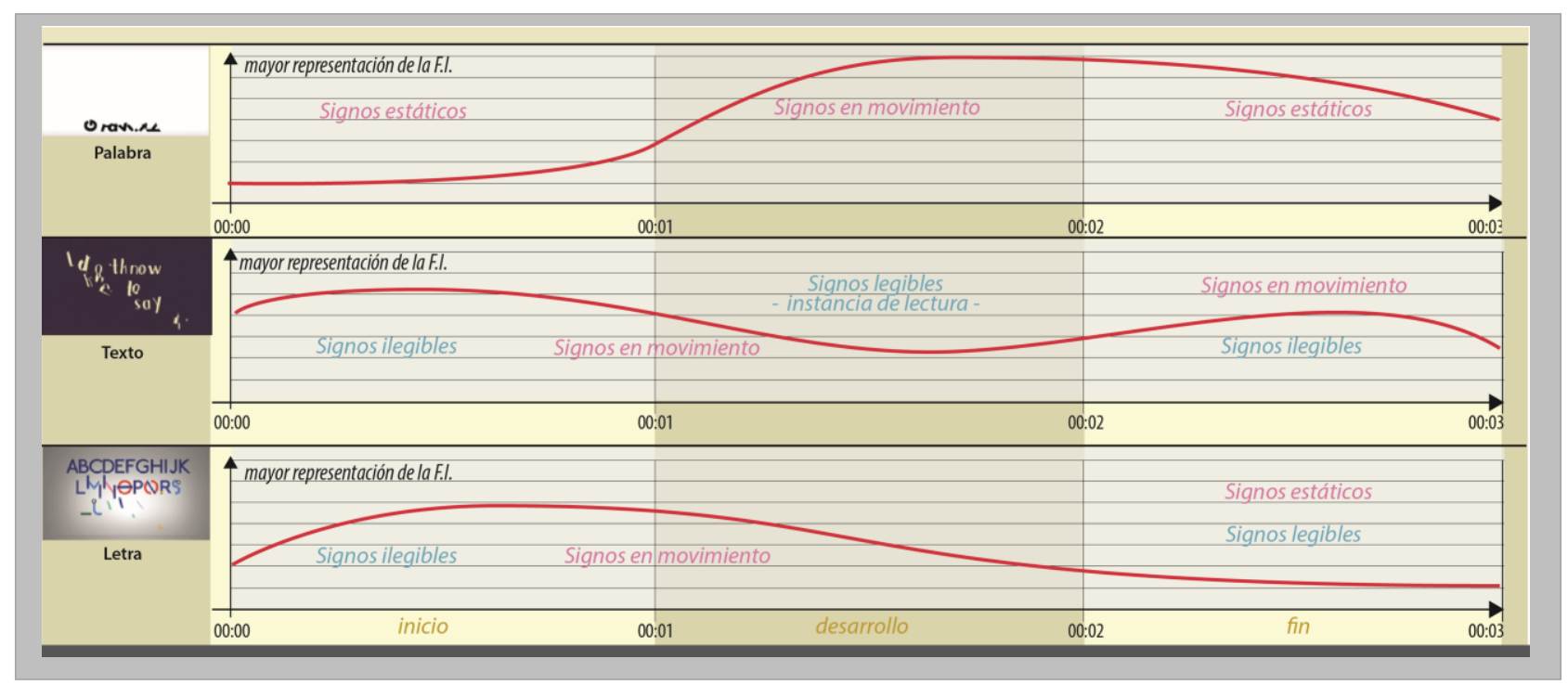

Figura 6: Cuadro comparativo de evolución de la curva que representa a la fuerza ilocucionaria en la duración de la animación de la escritura cinética en la pieza audiovisual.

Harris se pregunta "si los «mensajes» existen en un nivel abstracto antes de ser formulados por escrito, y si un «mismo» mensaje puede derivar de formulaciones distintas." (Harris, 1998, p. 24-25). Pues, a partir de estos análisis y en el contexto de la escritura cinética, se puede dar respuesta afirmativa a esta cuestión. Si bien el signo escrito, en tanto imagen de otra sustancia ya era capaz de trasmitir mensajes más allá de su ser lingüístico, aquí queda demostrado que a través de la tipografía en movimiento en las primeras instancias de la animación ya comunica el mensaje, o parte del mismo, antes que ese texto se formule. Es decir que, antes de transformarse en letra, esa imagen en construcción ya trasmite la fuerza ilocucionaria del contenido del texto que aparecerá cuando esa forma sea visible como signo de escritura y se pueda leer.

Al comparar las curvas que miden la expresión de la fuerza ilocucionaria en las tres piezas analizadas (ver Fig. 6 ) se puede leer que en los tres segundos de duración de los fragmentos seleccionados, la misma crece y decrece según la intensidad de acción de la animación. Es decir, hay momentos en que la curva está "baja" y otros en los que está "alta". Generalmente, cuando los signos de escritura se muestran estáticos la línea de la curva está en el primer nivel (de abajo para arriba), no en el nivel cero porque se supone que, siguiendo las afirmaciones de Gorodischer (2010), como los signos ya se identifican con una tipografía determinada están trasmitiendo, en parte, a la fuerza ilocucionaria. Sin embargo, es notable como en el momento que entran en juego la animación y el sonido, más allá de que los signos se muestren o no legibles, la curva se eleva. Aquí se puede decir que la expresión de la fuerza ilocucionaria se representa con mayor intensidad. Se puede interpretar con más precisión la intención del enunciador. Esto puede ocurrir en cualquier etapa de la animación, al principio, en el desarrollo o al final.

\section{DISCUSIÓN}

Este análisis es parte de una investigación mayor y aquí quedan aspectos aún para profundizar. Modalidades de producción que tienen que ver con las materialidades y tecnologías de los medios donde el texto es un híbrido construido desde herramientas multidisciplinares. Aspectos expresivos de la forma de escrituras efímeras que quieren llegar a través de los sentidos donde, por ejemplo, para que se puedan leer se involucra la experiencia corporal del espacio, no sólo virtual sino real, de ese espectador. Quien ya no sólo es lector sino también espectador. La escritura cinética es parte de esta hibridación de mensajes. Por esta razón, he aquí un puntapié para cuestionarse si la capacidad de la tipografía cinética para trasmitir la fuerza ilocucionaria de un texto tiene mayor incidencia en los atributos de su aspecto formal audiovisual que en los de su contenido verbal.

Esta investigación continúa en desarrollo y hasta ahora llena un lugar vacío en la temática. Con este escrito se pretende hacer un aporte teórico que invite a cuestionarse las distintas formas expresivas que puede adquirir la lengua escrita a la hora de comunicar en el contexto digital contemporáneo.

\section{AGRADECIMENTOS}

Al Comité Ejecutivo Internacional de SIGraDi. A mis Directores de Tesis Doctoral: la Dra. María del Valle Ledesma y el Prof. Arq. DG. Horacio Gorodischer; y a mi familia.

\section{REFERENCIAS}

Aumont, J. (1992). La imagen, Barcelona. Paidós Comunicación.

Austin, J. (2003). Cómo hacer cosas con palabras. Palabras y acciones. Paidós Segunda Edición, Bs. As.

Barthes, R. (1986). Lo obvio y lo obtuso, imágenes, gestos, voces, Ed Paidós Comunicación, s.a.

Brarda, M. (2016). Motion graphics design. La dirección creativa en branding de TV, Barcelona: Ed. Gustavo Gili.

Brownie, B. A New History of Temporal Typography: Towards Fluid Letterforms Journal of Design History (2014) 27 (2):167-181.

Gorodischer, H. (2010). Curiosidades Tipográficas. Santa Fe: Ediciones UNL

Harris, R. (1999). Signos de escritura. Barcelona: Ed. Gedisa, Primera Edición, 
Hillner, M. (2010). Tipografía virtual. Barcelona: Parramon Ediciones, S.A.

Ledesma, M. (2012) Enunciación de la Letra Un ejercicio entre Occidente y Oriente

Lee J., Forlizzi J., Hudson S., (2002); The Kinetic Typography Engine: An Extensible System for Animating Expressive Text, Carnegie Mellon University, Pittsburgh, USA.

Lupton, E. (2014). Tipografía en Pantalla. Barcelona: Ed. Gustavo Gili.

Oliveras, E. (2010). Arte Cinético y neocinetismo. Hitos y nuevas manifestaciones en el siglo XXI. Bs. As: Ed. Emecé Arte.
Olson, D. R. (1998). El mundo sobre papel. El impacto de la escritura y la lectura en la estructura del conocimiento. Barcelona: Ed. Gedisa, Primera Edición.

Ong, W. J. (1997). Oralidad y Escritura. Tecnologías de la palabra. México: Fondo de Cultura Económica, segunda reimpresión.

Sesma, M. (2004) Tipografismo. Barcelona: Paidós Diseño.

Woolman M. (2005). Tipografía en movimiento (Type in motion 2) Barcelona: Ed. Gustavo Gili. 